\title{
EL CUERPO FAMILIAR Y EL CUERPO PROPIO: CAMINOS INTERTEXTUALES ENTRE CÉSAR VALLEJO Y JOSÉ WATANABE
}

\author{
Miguel Ángel Malpartida Quispe* \\ Universidad Peruana de Ciencias Aplicadas \\ pchumima@upc.edu.pe
}

ReSUMEN: El artículo explora las convergencias pragmáticas, temáticas y alegóricas entre los textos ligados al ámbito familiar, la enfermedad y el auscultamiento del cuerpo, en las poéticas de César Vallejo y José Watanabe. Se evidencia, mediante el recorrido de alegorías comunes, tales como la del ombligo y la del vientre, la reelaboración que Watanabe realiza de las imágenes corporales de la tradición vallejiana para abordar la identidad y la confianza en el cuerpo. Asimismo, se devela un tránsito, común a ambos creadores, entre el cuerpo familiar, ligado a la enfermedad, y el cuerpo propio, fuente de sanidad y trascendencia.

Palabras clave: César Vallejo, José Watanabe, cuerpo familiar, cuerpo propio, alegoría.

* Miguel Ángel Malpartida Quispe estudió Literatura en la UNMSM. Ha publicado los poemarios Galería (Lima: Dedo Crítico, 2002) y Arte de nariz (Lima: Mesa Redonda, 2007), así como artículos de crítica literaria en revistas especializadas, nacionales e internacionales. Ha sido docente del curso Seminario de Literatura en la Universidad Católica Sedes Sapientiae. Actualmente, cursa la maestría en Literatura Peruana y Latinoamericana en la UNMSM y es docente en la Universidad Peruana de Ciencias Aplicadas.. 


\title{
THE FAMILY BODY AND THE SELF-BODY: INTERTEXTUAL PATHS BETWEEN CÉSAR VALLEJO AND JOSÉ WATANABE
}

\begin{abstract}
Aвstract: This article explores the pragmatic, thematic and allegorical convergences between texts related to the familiar sphere, illness and body checking in César Vallejo and José Watanabe's writings. It is evidenced by the path of common allegories, such as that of the navel and the belly, the work that Watanabe performs on the body images with vallejiana tradition to address identity and confidence in the body. It is also revealed a transition common to both writers, between the familiar body linked to disease, and the body itself, source of healing and transcendence.
\end{abstract}

KeYwords: César Vallejo, José Watanabe, family body, self-body, allegory

\section{ANTECEDENTES}

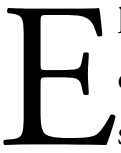

1 presente trabajo encuentra su origen intuitivo en una ya lejana conversación de sobremesa con José Watanabe, acaecida en septiembre de 2005. Durante la cena, el poeta laredino, a pedido de los que compartían su mesa, se animó a leer un poema. Eligió «El topo», texto incluido en el libro que acababa de publicar ese año, La piedra alada. Este poema plantea una alegoría de bestiario y en él, el yo lírico colectivo proyecta en el animal la experiencia de la enfermedad y las huellas con que esta lacera y deforma al cuerpo. El descubrimiento de este álter ego sufriente, huidizo y sangrante, sometido al sol y a la curiosidad del gentío, carente de "la simetría de los animales bellos», como se afirma en el poema «El lenguado», estremece a los espectadores de la situación lírica, los cuales finalmente enuncian: 
Nuestra mente demoraba, se estremecía, no podía creer que bajo la realidad estridente del sol hubiera otro animal de carne lastimada como la nuestra.

«Carne lastimada», tembló en los labios de José; «yo tengo mi carne lastimada», completó luego. "Puede resultar patético, dramático o exhibicionista, como Vallejo, que es bien exhibicionista con su carne herida [...] y es el más grande de los poetas peruanos», finalizó. Este breve indicio y la gran admiración por la obra de ambos poetas dieron origen a este artículo.

\section{EL CUERPO FAMILIAR}

El concepto de cuerpo familiar pertenece al ámbito de las Ciencias de la Salud. Señala las responsabilidades que recaen sobre la familia con respecto al cuidado del enfermo y cómo estas son realizadas en torno al cuerpo del sufriente. Se entiende, entonces, que la afectividad es la que congrega y mantiene unido al cuerpo familiar, que se erige como un basamento para afrontar la enfermedad, el sufrimiento y, eventualmente, la muerte.

De modo específico, en este ensayo, se operativiza el concepto para señalar un tópico que unifica, en la obra poética de César Vallejo y José Watanabe, una serie de imágenes corporales aparentemente dispersas que refieren a los conceptos de la enfermedad, el miedo, el dolor y la muerte.

\section{LA ENFERMEDAD}

En la obra poética de César Vallejo, la enfermedad se presenta en relación metonímica con los significantes del dolor y la muerte, los cuales abarcan 
todos los poemarios, desde Los heraldos negros (1919) y la experimentación de la orfandad humana, metafísica y corporal, religiosa y erótica; hasta concentrarse en Poemas humanos (1939) y España, aparta de mi este cáliz (1940), en los cuales el dolor y el sufrimiento se extienden más allá del cuerpo, y mil cuerpos, hasta alcanzar, incluso, la indiferenciación con respecto a los objetos. De allí, el camino hacia la otredad es irreversible y, con ello, adviene la universalidad de lo humano mediante la solidaridad, que todo lo impregna mediante la experiencia de un sufrir común, cotidiano, heroico y transformador del mundo.

Por otro lado, la enfermedad como tema está presente en toda la poesía de Watanabe, desde Álbum de familia, de 1971 (verbigracia, «Poema trágico con dudosos logros cómicos», "Informe para mi hermano muerto en la infancia» y «Las manos») hasta Banderas detrás de la niebla, su último poemario, publicado el 2006 («Responso ante el cadáver de mi madre», «Orgasmo» y «Riendo y nublado»). Sin embargo, existe un poemario en el marco de toda su producción, El huso de la palabra (1985), que incluye una sección específica sobre los rigores de la enfermedad del cuerpo; llamada «Krankenhaus» (hospital, en alemán) y se compone de nueve poemas. Todos ellos se refieren, desde distintas perspectivas, al tránsito corporal hacia la muerte, y sostienen una duda general: ¿será suficiente el cuerpo para impedirla?

\section{EL CUERPO FAMILIAR Y LA IDENTIDAD: ALEGORÍA DEL OMBLIGO}

Los temas de la enfermedad, el sufrimiento y la muerte se extienden, en el caso de ambos poetas, desde sus primeros libros, y se encuentran estrechamente vinculados al primero de los cuerpos sociales, el de la familia. De este modo, 
el espacio íntimo del hogar se convierte en el ámbito del dolor primigenio, el de la primera sospecha del «desmembramiento» familiar. Las imágenes del cuerpo y la familia concentran los elementos materiales que permiten una interpretación paralela de los dos mundos representados. Asimismo, colocan en relieve la influencia que la tradición erigida por César Vallejo ejerció, en cuanto a sus elementos temáticos, imágenes y recursos estilísticos, en la obra de José Watanabe.

La primera coincidencia notable se presenta entre dos textos: «Encaje de fiebre», soneto que pertenece al apartado «Canciones de hogar» de Los heraldos negros y "La impureza», poema de la sección "Krankenhaus», de El huso de la palabra. Ambos establecen similitudes debido a una situación lírica en común: los locutores se remontan hacia la primera experiencia de la enfermedad mortal para auscultar los elementos salvíficos de los cuales asirse. Mientras que Vallejo se aposenta en el tiempo presente, desde el inicio, como una estrategia para vivificar un evento remoto; Watanabe propone otro modo de actualización: inicia con el presente del cuerpo adulto, enfermo, y, gradualmente, va internándose en el pasado infantil, más bien benéfico:

Por los cuadros de santos en el muro colgados mis pupilas arrastran un ay! de anochecer; y en un temblor de fiebre, con los brazos cruzados, mi ser recibe vaga visita del Noser.

Una mosca llorona en los muebles cansados yo no sé qué leyenda fatal quiere verter [...] 
Otra vez despiertas con el cuerpo poco, bien poco.

Otra vez tu vida oscila en el monitor cardíaco pero más en tu miedo.

Ya no es la hipocondría. Ya te saltó el verdadero animalito.

Mas no patetices. Eres hijo de. No dramatices.

¡Mira que tu miedo es la única impureza en este cuarto aséptico!

O nunca conseguiré realmente ser hijo de?

(«La impureza»)

Los dos poemas, así segmentados, coinciden en presentar la certeza de la enfermedad (una fiebre, en el primer caso; un cáncer, «el verdadero animalito", en el segundo); y detallar la posición ensimismada del sufriente que experimenta la amenaza de la muerte en un cuerpo deprimido. Para ambos sujetos, la muerte es la disolución completa y no una parte integral de la vida. Para el primero es el Noser, una fusión de palabras que denota la vacuidad ontológica personificada, la muerte como un absoluto; para el segundo es el No ser hijo de, es decir, el carecer de raíz en el mundo, la imposibilidad inicial de asumir la identidad familiar para afrontar el sufrimiento. Se hace evidente una coincidencia fónica en las palabras que nombran la disolución y niegan la vida, lo cual patentiza la reelaboración de José Watanabe, a partir de la adjunción vallejiana.

En ambos casos, el temor al acabamiento es evidente. La mosca, en el poema de Vallejo, es un mensajero de la corrupción, como ocurre también en "Las ventanas se han estremecido", de Poemas humanos; en el de Watanabe, el monitor cardíaco es el agente impersonal de la muerte, el aparato de fría ciencia que otorga el veredicto final, tal como aparece en un poema posterior del autor, «Interior de hospital», en Historia natural (1994). 
Asimismo, el segundo fragmento ahonda en la alegoría del miedo como una mácula, como una afrenta a la dignidad en el espacio aparentemente pulcro del cuerpo, alegorizado y transmutado en la habitación de hospital.

Por otro lado, con respecto a las figuras pragmáticas, el yo lírico de «Encaje de fiebre» emplea la primera persona, lo cual le permite exhibir abiertamente su interioridad; en cambio, el yo lírico de «La impureza» alterna un desdoblamiento en tercera persona con la primera; ello le permite ocultarse $y$, sin embargo, ahondar en su vida psicológica y auscultar sus temores de modo riguroso. Para ambos casos, los segmentos mostrados a continuación señalarán al cuerpo familiar que acude al cuerpo del enfermo. A su vez, dicho sufrimiento se compondrá también por las figuras de los padres:

En un sillón antiguo sentado está mi padre.

Como una Dolorosa, entra y sale mi madre.

$\mathrm{Y}$ al verlos siento un algo que no quiere partir.

Porque antes de la oblea que es hostia hecha de Ciencia, está la hostia, oblea hecha de Providencia.

Y la visita nace, me ayuda a bien vivir [...]

(«Encaje de fiebre»)

El japonés

se acabó «picado por el cáncer más bravo que las águilas», sin dinero para la morfina, pero con qué elegancia, escuchando [...]

las notas [...] del kotó

de la Hora Radial de la Colonia Japonesa.

Y la serrana

que si descubre que miran condolidamente su vejez

protesta con el castellano castizo que se conserva de Otuzco para 
adentro:

«Más arrugas hay en tus compañones que en mi majoma, carajo» y asombrosamente sigue matando pollos, cuyes, cabritos, sin un gesto compasivo y diciendo , como si dictara la suprema lección moral: «Deja el tiesto sobre las brasas, hijo, para que coja más temple».

(«La impureza»)

En los dos poemas, el yo lírico hijo recurre a la memoria familiar. En el primer caso, utiliza las imágenes de la tradición cristiana debidas especialmente a la madre, que es apreciada como la Virgen del Viernes Santo, lo cual entabla una alegoría con la sagrada familia, en la que el yo lírico asume la posición crística. Desde esta tradición, el deseo de vivir y superar el mal se sostiene en la religiosidad; es una resurrección que se ritualiza en la unción de los enfermos. El remedio espiritual, la hostia, en el poema es enteramente material; y es administrada por la sabiduría divina, en desmedro de la ciencia y sus tratamientos. La fe invierte el final trágico que se esperaba: el bien morir de los cristianos viejos se transforma dialécticamente en el bien vivir, que se hace realidad precisamente debido al encuentro con el Noser. El enfermo no se recupera porque niegue la muerte; recobra la vida, precisamente, gracias a dicha amenaza y a la actitud de entrega esperanzada. Por otro lado, en el poema de Watanabe, el No ser hijo de es confrontado con la dos vertientes culturales del autor implícito. El yo lírico, ausculta sus recuerdos más preciados, los paradigmas que sustenten su actitud ante el riesgo de No ser hijo de nadie (el equivalente extendido del Noser, negación desde el interior mismo del ser, inexistencia absoluta). Las tradiciones culturales son nombradas mediante los posibles gentilicios y no a través de los nombres propios. 
El padre japonés es estoico, heredero de la tradición budista popular del bushido, como comenta el autor en el testimonio titulado «Elogio del refrenamiento", por tanto, busca la dignidad del cuerpo en el momento de la muerte y contiene sus expresiones para coincidir con la naturaleza del mundo, el cual está libre de exageraciones. El yo lírico entabla lazos intertextuales con un poema de su primer libro: «Poema trágico con dudosos logros cómicos», en él, irónicamente, lo llama además «Lamentable Prometeo».

La serrana, la madre, por su parte, al igual que la madre vallejiana, administra los conocimientos tradicionales y se entroniza (como una «reina vieja», se afirmará en el poemario Historia Natural), guardiana severa de la tradición popular. Es ruda en su expresión, si se la compara con el padre silente y mesurado; sin embargo, comparte con él la dignidad frente a los signos de la enfermedad y la muerte. Por ello, se enfrenta ante quien le brinda compasión, como el yo lírico hijo, que debe buscar la respuesta en sus compañones ${ }^{1}$, una palabra, que ya Vallejo, trujillano como lo fue Watanabe, empleó en "Epístola a los transeúntes» de Poemas humanos: "Reanudo mi día de conejo, / mi noche de elefante en descanso. // Y entre mí, digo: [...] estas son mis sagradas escrituras, / estos son mis alarmados compañones.». Asimismo, mediante la alegoría del tiesto, la madre recomienda al hijo enfermo asumir los problemas para poder enfrentarlos. Como se observa, el poema de Watanabe tiende hacia la resolución narrativa del conflicto. Se espera que el locutor adopte alguna de las dos vertientes o ambas:

1 En el área geográfica del norte peruano, compañones designa a los testículos, y majoma, al rostro. De forma particular, el segundo vocablo fue difícil de rastrear y aparece como una expresión de la lengua nativa, usual en Celendín, Cajamarca (departamento que colinda al sur con La Libertad) (cf. Carrasco, 2008 y Chávez, 2005). 
Ellos no vendrán, pues, a tomar tus manos

y acaso estás a punto de no ser hijo de nadie. Entonces

el pensamiento imposible que te viene y te deja va haciéndose posible. Acógelo: ten miedo, ten miedo,

y justamente con tu miedo quizá vuelvas a ser hijo de, como antes, niño,

cuando ellos todavía te abrazaban con alguna piedad.

Por otra parte, el último segmento del poema expone la resolución de la alegoría de la impureza. Esta representa la enfermedad y el miedo que mancillan el cuerpo, y que debe ser aceptada como una posibilidad, para evitar la muerte. El acoger la mancha significa recobrar los sentimientos humanos elementales y la confianza en el cuerpo, aprendidos en la infancia, y asumir la posibilidad del dolor con entereza, tal como lo hicieron los padres. Esta opción, al mismo tiempo, le permite al yo lírico fundar su identidad, para poder socorrer al cuerpo carente, el cuerpo poco de la enfermedad, y completar con dignidad la elipsis de su origen: ser hijo de Harumi Watanabe y de Paula Varas.

El poema está sostenido, desde el origen, en la triada enfermedadsufrimiento-muerte que se acrisola en las referencias al cuerpo familiar, común a ambos poetas. Las implicancias de este texto atraviesan la obra de Watanabe y configuran, en un poema posterior, "El vado» incluido en la sección «Arreglo de cuentas» de La piedra alada (2005), una imagen del sincretismo cultural:

\author{
[...] Cuida de dejar hundida la vara \\ con gratitud \\ en la otra orilla: otro viene: \\ acaso mi padre \\ que en las tierras amarillas busca sandías silvestres, \\ acaso yo / que regreso, retrasado y viejo,
}


mirando ansioso mi pueblo que tras el río ondula o se difumina en el vaho solar.

Allí, según su costumbre, sembraron mi ombligo entre la juntura de dos adobes / para que yo tuviera patria. [...]

En este poema, el simbólico reencuentro con tres elementos: el padre, el pueblo (otra forma de nombrar a la madre) y el pasado, se hace posible, y se resuelve la incertidumbre de «La impureza». La posición ante la muerte llega a adoptarse cuando el cuerpo es aceptado amistosamente: no como un límite (símbolo de la enfermedad, en los poemas del autor), sino como un pasaje hacia la trascendencia desde la materialidad. La actitud, el deseo de perseverar, es la herencia que el hijo recibe de las manos que lo acogen. El ombligo sembrado, ${ }^{2}$ por tanto, es el reconocimiento de un nuevo

2 La imagen del ombligo es enunciada por César Vallejo en "Epístola a los transeúntes», de Poemas humanos. Alberto Escobar (1973: 244) observa que, en este poema, el sujeto vallejiano funda su naturaleza, representada «con sus potencialidades pero también con sus flaquezas y límites», en un principio material que sustenta lo metafísico-religioso de su existencia. Por otro lado, resulta de especial interés que, en dicho texto, tal como lo señala Américo Ferrari (1997: 145-147), el yo lírico reconozca que su identidad humana se sustenta en el dolor corporal de su ser, fragmentado por la muerte y cuyo elemento enumerado más notable es el «hombligo». De modo específico, acerca de esta imagen, Antonio Moreno (2005: 569) opina que la prótesis de la «h» distingue la naturaleza humana de la animal. Creemos que la significancia del recurso empleado es más honda. El análisis de la imagen revela los siguientes sentidos: representa (a) la impronta y el estigma de la herencia humana, (b) el alejamiento del Génesis, revertido por la hache que humaniza al ser adánico inicial y (c) la focalización en el vientre. Asimismo, refiere, en el verso 26, la simiente de una arquitectura corporal, una juntura de dos «ladrillos» fundamentales (dualidad cuerpo y alma, con preeminencia de la materia): «Pero cuando yo muera / de vida y no de tiempo, / cuando lleguen a dos mis dos maletas, / [...] éste ha de ser mi cuerpo solidario / por el que vela el alma individual; éste ha de ser / mi hombligo en que maté mis piojos natos, / ésta mi cosa cosa, mi cosa tremebunda. // [...] y, puesto que he existido entre dos potestades de ladrillo, / convalezco yo mismo, sonriendo de mis labios. [...]». De acuerdo a ello, no es casual que José Watanabe reelabore la relación ombligo-ladrillo para representar la escisión y la unicidad cultural de su origen mestizo. 
origen, ya sostenido y sólido en la arquitectura corporal de dos adobes (el padre y la madre): una patria que se aposenta en el cuerpo familiar y que hace del cuerpo propio una vía salvífica.

En ello consiste el ajuste de cuentas. Es la resolución de los antiguos conflictos que se extienden desde su primer poemario, Álbum de familia. ${ }^{3}$ Así también lo asume Vallejo, aunque de forma más exhibicionista y dramática, como afirmaba José Watanabe. En «El alma que sufrió de ser su cuerpo», que pertenece a Poemas humanos, el yo lírico se desdobla en un tú de la reflexión, para reprenderse y conjurar el miedo que lo asalta, de improviso. Las preguntas finales constituyen el tránsito del cuerpo familiar al cuerpo propio, focalizado en el vientre:

Tú sabes lo que te duele,

lo que te salta al anca,

lo que baja por ti con soga al suelo [...]

Y tú lo sabes a tal punto,

que lo ignoras, soltándote a llorar.

Tú, luego, has nacido; eso también se ve de lejos, infeliz y cállate, y soportas la calle que te dio la suerte y a tu ombligo interrogas: ¿dónde? ¡cómo? [...]

3 El yo lírico de «Flores de plástico» expresa la conciencia de la finitud del siguiente modo: «Esa inmemorial premonición / que estremeció al hombre ante la flor marchita» (Watanabe 2008: 31). 


\section{EL CUERPO PROPIO: ALEGORÍA DEL VIENTRE}

La imagen del vientre, como concentración de las funciones corporales básicas y como portador de sabiduría, es común a la obra de ambos poetas. Funciona como una oposición al trabajo de la mente y a la conformación de un yo racional. El yo lírico que se sustenta en el cuerpo, adquiere en ambos casos, el poder de la sobrevivencia y luego, el de la trascendencia. Se anulan por completo las cavilaciones metafísicas y surge una verdad material, debido a que el sujeto se ampara en el cuerpo, se recubre de él como en un gran vientre. Dicha imagen extiende sus raíces en la tradición literaria peruana desde que César Vallejo la representa en dos textos de Poemas humanos:

Ello es que el lugar donde me pongo

el pantalón, es una casa donde

me quito la camisa en alta voz

[...] Ahora mismo hablaba

de mí conmigo,

[...] y he, luego, hecho el traslado, he trasladado

[...] el lado derecho de la vida al lado izquierdo;

más tarde, me he lavado todo, el vientre,

briosa, dignamente;

he dado vuelta a ver lo que se ensucia [...].

(«Ello es que el lugar donde me pongo»)

Hoy me gusta la vida mucho menos,

pero siempre me gusta vivir: ya lo decía.

Casi toqué la parte de mi todo y me contuve [...] 
Hoy me palpo el mentón en retirada

y en estos momentos pantalones yo me digo:

¡Tanta vida y jamás! / ¡Tantos años y siempre mis semanas!

[...] en fin, mi sér parado y en chaleco

[...] Tanta vida y jamás me falla la tonada!

¡Tantos años y siempre, siempre, siempre!

[...] Que es verdad que sufrí en aquel hospital que queda al lado

y está bien y está mal haber mirado

de abajo para arriba mi organismo.

Me gustará vivir siempre, así fuese de barriga [...].

(«Hoy me gusta la vida mucho menos»)

Como se observa en ambos fragmentos, la continuidad de la vida está representada por los repetitivos cambios de atuendo, de pantalones y camisas, que conminan al locutor a asumir una existencia social y pública rutinaria. Sin embargo, corresponde al espacio del hogar el auscultamiento del cuerpo propio. En el primer poema, el reordenamiento del entorno a partir de sí mismo instaura una alegoría que identifica al cuerpo con su continente: la casa. El cuerpo se convierte en espacio y sus componentes, los objetos, en los órganos auscultados. Asimismo, lavarse el vientre excede el hecho rutinario y se transforma en una posibilidad de encuentro del sujeto con aquello que lo hace proseguir en el mundo.

En el segundo poema, el yo lírico se sorprende de su continuidad, de la prolijidad de su cuerpo, y también se ausculta. Examina detalladamente el rostro (el mentón y el perfil en Vallejo son indicadores de la edad madura, como en «El momento más grave de la vida») y su cuerpo propio, de 
abajo hacia arriba, desdeñosamente, desde lo aparentemente inferior hasta la supremacía racional. El resultado es similar: retorna la confianza en el cuerpo, especialmente ante el recuerdo de la enfermedad padecida en el hospital, que ha cuajado como una cicatriz, y a la que se hace referencia en otro poema («Las ventanas se han estremecido», que también ofrecen una elaboración de la imagen, aunque más trágica). Finalmente, la respuesta se halla en el cuerpo, en el vientre que continúa con su labor y sobre el cual el locutor fundamenta su decisión equilibrada, su «Me gustará vivir siempre, así fuese de barriga», tal como lo expresa en el poema «Hoy me gusta la vida mucho menos».

La recurrencia al vientre como un órgano protector se retoma en la poética de José Watanabe. En el poema de la sección «Krankenhaus» "Como el Pejesapo", se plantea, al igual que en los poemas vallejianos, un auscultamiento inicial del cuerpo propio, en busca de la razón de la continuidad biológica.

Nunca escuchaste canto más razonable

que el de los pájaros que anoche huían de la tormenta:

«Más vale/ estar asido/ del aire».

Porque en el peligroso borde palpas verso como ramita providencial

o frase de la filosofía como piedra para apoyar el pie.

Sí, más te hubiera valido aprender a asirte del aire.

Tendido, tu cuerpo suena sus tripas y te recuerda que

aún te quedan tus humildes voces

vegetativas. Sonríes

y con ternura maternal oyes tu borborigmo y tu pedo,

y te serenas:

en el peligroso borde te afirmas como el peje-sapo en la roca marina, 


\section{MIGUEL ÁNGEL MALPARTIDA QUISPE}

con el vientre.

Callada tu mente y su prestigioso trabajo, descubres, en el peligroso borde, que tu cuerpo es más inteligente y que es tuyo y de todos. Todo cuerpo es tótem.

Levántate y muestra tu desnudez al alba que ya empieza.

A las 7 los cirujanos te abrirán el pecho con sus escalpelos.

No morirás: tus voces vegetativas siguen sonando y ya son (y ya eres) parte del rumor panteísta que viene del bosque y, al parecer, de un alba más remota.

En la situación lírica, la amenaza de la enfermedad atormenta al locutor, el cual espera temeroso una operación de pecho abierto. Va a permitir que sus entrañas se entreabran para ser esculcadas por la ciencia. El rechazo a la deshumanización de la terapéutica y la desconfianza en la ciencia es otra característica que vincula los poemas de la enfermedad en las obras de Vallejo y Watanabe.

La reflexión inicial del yo lírico fracasa rotundamente cuando estriba en la mente racional, representada por el prestigioso trabajo del cerebro o por el ejercicio de la palabra poética. Ambos, racionalidad y arte, son incapaces de conjurar el temor a la muerte. Sin embargo, se va gestando una certeza, cuando el locutor atiende a una sabiduría más trascendente: la del cuerpo.

En el poema de José Watanabe, del vientre enfermo surgen las llamadas "voces vegetativas», sonidos involuntarios que inician un diálogo sin mediación de lengua alguna. Esta comunicación formula un lenguaje enteramente material, carente de signos convencionales: es un acto privado y al mismo tiempo universal. En su mensaje, la universalidad de las funciones corporales anima al locutor hacia la vida, es decir, procura su sobrevivencia. 
Le permite sostenerse, asimismo, en la esperanza de la trascendencia cósmica y la solidaridad humana (tema tan cercano a España, aparta de mi este cáliz, de Vallejo): «Tu cuerpo es más inteligente y que es tuyo y de todos. Todo cuerpo es tótem».

Como se observa, el vivir «así fuese de barriga» del yo lírico vallejiano se reelabora en el deseo de afirmarse «como el pejesapo en la roca marina, con el vientre», en el poema de José Watanabe. Los sujetos de ambos textos adoptan una actitud similar ante «el peligroso borde» entre la enfermedad y la muerte. Se abocan a la sobrevivencia y retoman la confianza en el cuerpo propio. Asimismo, se alejan de las reacciones iniciales, cuando debían recurrir al cuerpo familiar o abandonarse a la desventura. Al igual que en los poemas de «Krankenhaus», signados por la estoicidad del padre japonés, el yo lírico vallejiano, en los poemas relativos a la enfermedad, condena el llanto y la exageración, que conllevan al ensimismamiento: «sufro con gran cuidado, / a fin de no gritar o de llorar, ya que los ojos / poseen, independientemente de uno, sus pobrezas, / quiero decir, su oficio, algo / que resbala del alma y cae al alma», enuncia en "Hoy me gusta la vida mucho menos...».

El poema de Watanabe plantea una imagen sincrética, aportada por la tradición vallejiana; la del vientre. Esta consolida intertextualmente una actitud de los hablantes ante el sufrimiento y la muerte: el retorno al cuerpo, como un elemento totémico. Para lograrlo, el locutor debe auscultar su materialidad, autoreconocerse en ella, recobrarla. Solo así puede encontrarse con los otros y acceder a una humanidad más integral. 


\section{BIBLIOGRAFÍA}

Carrasco Ligarda, Rosa 2008
«Celendinismos». En Documentos del II Congreso de Lexicología Pedro Benvenutto Murrieta. Página web de la Academia Peruana de la Lengua. Disponible en <http://academiaperuanadelalengua.org/ iicongreso/carrasco/celendinismos $>$. Consulta hecha en 12/03/2012.

CoYné, André

1989

César Vallejo. Lima: SEA.

Chávez Silva, Jorge A. 2005

«Fabla celendina, celendinense o shilica. Recopilación». En Celendín, pueblo mágico. Un pasado, una historia, un destino. Disponible en <http://celendin.free.fr/PuebloMagico/page15/ page $85 /$ page $85 . h t m l>$. Consulta hecha en $11 / 03 / 2012$.

EsCOBAR, Alberto

1973

Cómo leer a Vallejo. Lima: P. L. Villanueva Editor.

Ferrari, Américo

1997

El universo poético de César Vallejo. Lima: Universidad de San Martín de Porres. 
López Casanova, Arcadio

1994

El texto poético: teoría y metodología. Salamanca: Ed. Colegio de Espańa.

Moreno, Antonio

2005

César Vallejo. Poesía completa. Madrid: Akal.

VALLEJO,César

1998

Poemas completos. Lima: Petroperú.

WaTANABE, José

1999

«Elogio del refrenamiento». En Quehacer N. 117.

2008

Poesía completa. Valencia: Pre-textos. 